\title{
Evaluation model of landslide hazards induced by the 2008 Wenchuan earthquake using strong motion data*
}

\author{
Xiuying Wang ${ }^{1, \star}$ Gaozhong $\mathrm{Nie}^{2}$ and Mujun $\mathrm{Ma}^{3}$ \\ ${ }^{1}$ Institute of Crustal Dynamics, China Earthquake Administration, Beijing 100085, China \\ ${ }^{2}$ Institute of Geology, China Earthquake Administration, Beijing 100029, China \\ ${ }^{3}$ National Earthquake Response Support Service, Beijing 100049, China
}

\begin{abstract}
Landslides induced by the 2008 Wenchuan earthquake in the Longmenshan area were relatively well instrumented, which makes it possible to investigate the landslides using ground motion records. Firstly, this paper analyzes the data from Wenchuan earthquake on both regional and local site scale. The analyses show that the Newmark accumulative displacement calculated from the ground motion recorded in a particular geological hazard zone corresponds to the hazard intensity in that zone; the larger the displacement, the more serious the geologic hazard. The calculated result also shows that the displacement is related to the Arias intensity, which represents the total energy released during the earthquake at the observation site. Secondly, this paper constructs an evaluation model of Newmark displacement calculated with Arias intensities to estimate the subsequent slope failure resulting from the earthquake. The calculated results based on the model fit well with the distribution of actual landslides, suggesting that this method is useful for hazard evaluation. Therefore, this type of model can be used for estimating regional-scale distribution of earthquake-induced landslides and their associated hazards immediately after an earthquake.
\end{abstract}

Key words: Wenchuan earthquake; earthquake-induced landslide; evaluation model; Arias intensity; earthquake intensity

CLC number: P315.9 Document code: A

\section{Introduction}

The $M_{\mathrm{S}} 8.0$ Wenchuan earthquake of 12 May 2008 induced severe landslides and caused great economic and human losses. Much research has subsequently been carried out concerning, not only the earthquake, but also geological disasters triggered by the earthquake (e.g., Huang and Li, 2008; Liu, 2008; Yin, 2008).

The Wenchuan earthquake is not the only one that induced serious landslide hazards, in fact earthquake-induced landslide hazards are widely distributed in China. According to statistical data from earthquakes that have occurred since 1949, over 20 provinces and regions have records of such disasters,

\footnotetext{
* Received 28 December 2010; accepted in revised form 18 May 2011; published 10 June 2011.

† Corresponding author. e-mail: xiuyw@sohu.com

(c) The Seismological Society of China and Springer-Verlag Berlin Heidelberg 2011
}

especially in the western mountainous areas prone to earthquakes (Wang and Nie, 2009a).

Unfortunately, studies on earthquake-induced landslides have been rarely reported in China to date, especially those based on the measurement of ground motion parameters.

In the previous researches, earthquake intensity was taken as an earthquake triggering factor (Zhou and Zhang, 1994; Ding et al., 2000; Wang, 2003). But, it may be affected by the personal biases of the observers due to the qualitative criteria involved $(\mathrm{Hu}, 2006)$. Therefore, as far as the same earthquake is concerned, inconsistency and discrepancy may exist in its intensities from different observers. Moreover, landslide number and extent themselves are often part of the criteria used to assess the earthquake intensity (Hu, 2006). For these reasons, evaluations of earthquake-induced landslides from those studies using earthquake intensity are not 
highly reliable.

Up to now studies on ground motion data from the earthquakes such as the 1987 Loma Prieta earthquake, the 1994 Northridge earthquake, and the 1999 Chi-Chi earthquake, suggest that ground motion is one of the most important factors resulting in earthquake-induced landslides; ground motion parameters are closely related to the distribution of earthquake-induced landslides. Therefore, ground motion parameters have subsequently been introduced into more and more earthquakeinduced landslide investigations (e.g., Harp and Wilson, 1995; Liao, 2000; Keefer, 2002; Khazai and Sitar, 2004; Pradel et al., 2005; Jibson, 2007; Saygili and Rathje, 2008).

However, due to lack of ground motion data that correspond to earthquake-induced landslides, previous research generally compared ground motion data from earthquakes with records with landslides induced by earthquakes without records. It is easy to understand that the results of such studies may be problematic, since the source, path of propagation, and local site conditions have great influence on ground motion records (Hu, 2006). Two earthquakes with similar magnitude and epicentral distance to the receiver may produce quite different site responses. Therefore, conclusions arrived at by comparing data from different earthquakes at different locations may be deficient.

The $M_{\mathrm{S}} 8.0$ Wenchuan earthquake triggered numerous landslides (Yin, 2008; Huang and Li, 2008; Liu, 2008), and a large quantity of strong motion data were recorded (Li et al., 2008; Yu et al., 2008). This provides an excellent opportunity to study the relationships between earthquake-induced landslides and ground motion parameters from a single strong earthquake, and also to study the landslides' distribution characteristics and their relation with ground motion parameters in southwestern China.

Prior to the investigation presented in this paper, we studied the relationships between landslides induced by the Wenchuan earthquake and various ground motion parameters such as PGA, PGV, Arias intensity $\left(I_{\mathrm{a}}\right)$, and the lower and upper triggering limits of each of these parameters (Wang, 2009; Wang and Nie, 2009a, b; Wang et al., 2009, 2010a, b, c). We found that PGA, PGV and $I_{\mathrm{a}}$ are closely related to earthquake-induced landslides on both regional and local scales. Based on these studies, a quantitative evaluation model of landslides induced by the Wenchuan earthquake was built up to assess the regional-scale hazard. This will be useful for site selection and earthquake-induced landslide hazard zoning for post-earthquake reconstruction work in the earthquake-hit area.

\section{Data and methods}

Since Arias intensity $\left(I_{\mathrm{a}}\right)$ is considered the most relevant ground motion parameter for studies of earthquake-induced landslides (Harp and Wilson, 1995; Jibson et al., 2000; Wang et al., 2009), this paper employs $I_{\mathrm{a}}$ as an estimation parameter in the model.

\subsection{Definition of Arias intensity}

Arias intensity (Arias, 1970) is defined as the sum of all the squared acceleration values from a strong motion record. It is a measure of the energy dissipated at a site by shaking.

$$
I_{\mathrm{a}}=\frac{\pi}{2 \mathrm{~g}} \int_{0}^{T_{\mathrm{d}}}[a(t)]^{2} \mathrm{~d} t,
$$

where $a(t)$ is the acceleration value from the record, $T_{\mathrm{d}}$ is the duration of the shaking, and $g$ is the acceleration due to gravity. $I_{\mathrm{a}}$ is in $\mathrm{m} / \mathrm{s}$.

From equation (1) we can see this parameter incorporates both amplitude and duration information, making it more capable of representing the shaking intensity of ground motion than other parameters, such as PGA and PGV, in which only the instantaneous maximum values are selected to represent the shaking intensity. Therefore, this parameter is more suitable for evaluations of surface damage, including earthquake-induced landslides of course.

\subsection{Newmark analysis}

The Newmark analysis is often used in slope stability analyses in conjunction with seismic activity. For this method, the slope is taken as a rigid friction block. When the ground acceleration exceeds the slope's critical/yield acceleration $\left(a_{\mathrm{c}}\right)$, the threshold ground acceleration necessary to overcome the block sliding resistance, down-slope movement will be initiated and permanent movement of the block will begin to accumulate. If the critical acceleration of the slope is known, Newmark displacement can be calculated by double integrating all those values exceeding the slope's critical acceleration $\left(a_{\mathrm{c}}\right)$. The Newmark calculation process can be expressed as

$$
D_{\mathrm{N}}=\iint\left[a(t)-a_{\mathrm{c}}\right] \mathrm{d} t \mathrm{~d} t,
$$

where $D_{\mathrm{N}}$ is the Newmark displacement, $a_{\mathrm{c}}$ is the critical acceleration, and $a(t)$ is the ground acceleration time history. 
With this method, accumulated permanent displacement is calculated over the whole shaking process, and the calculated result is used to analyze the slope stability. Both lab and field investigations have proved that Newmark analysis is accurate when the slope geometry parameters, geotechnical controls, and ground acceleration time history are provided correctly. For example, the measured displacement of a landslide, triggered by the 1979 Coyote Lake earthquake in California, is in excellent agreement with the Newmark displacement calculated from the acceleration time history (Wilson and Keefer, 1983).

The critical acceleration, $a_{\mathrm{c}}$, must be obtained in order to calculate the Newmark displacement. One way to determine $a_{\mathrm{c}}$ is to use the static safety parameter $F_{\mathrm{s}}$, i.e., a different acceleration is applied to the slope, and then the acceleration value that makes $F_{\mathrm{s}}$ equal to 1.0 is the critical acceleration. Slope critical acceleration signifies that the slope may fail when the ground motion acceleration reaches or exceeds this value. It is the maximum ground motion acceleration that the slope can withstand when subjected to an earthquake, and it is related to the slope geotechnical parameters (shear strength, unit weight, pore water pressure, etc.), and the slope geometry. It can be calculated by the following equation (Wilson and Keefer, 1983):

$$
a_{\mathrm{c}}=\left(F_{\mathrm{s}}-1\right) \mathrm{g} \sin \theta
$$

where $F_{\mathrm{s}}$ is the static factor of safety, and $\theta$ is the slope angle.

The Newmark displacement is often used as an index of slope failure (Jibson, 2007); the larger is the Newmark accumulated displacement, the greater the probability of slope failure is. When the displacement exceeds the maximum displacement limit a slope can withstand, it is quite possible that a landslide will be triggered. Therefore, the failure of a slope after an earthquake can be deduced from the accumulated displacement, and the results evaluated by this method are much more reliable than those by PGA only. This is because it is not necessary to accumulate sufficient displacement if the PGA does exceed the critical acceleration, and the slope may resume its original status after undergoing a vibration episode.

\subsection{Distribution of strong motion data}

Before the Wenchuan earthquake, a large number of ground motion instruments were deployed in the Longmenshan area. Therefore, a large quantity of acceleration records were obtained from both the main shock and its aftershocks (Li et al., 2008; Yu et al., 2008). Nearly 40 groups of records from the main shock were selected for this study. Their stations are distributed along the earthquake rupture trace both on the hanging wall and footwall, corresponding well with the most serious earthquake-induced geological disaster areas. Figure 1 shows the distribution of these strong motion stations

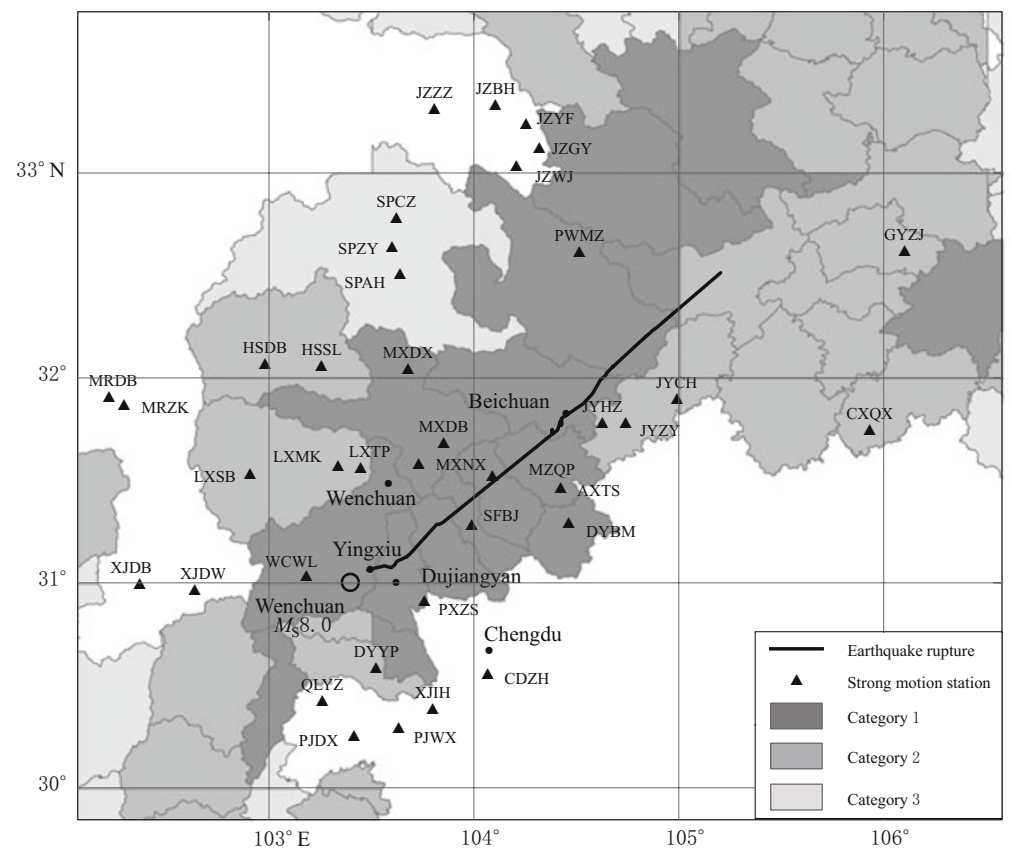

Figure 1 Distribution of geological disaster zones and ground motion observation stations in the Longmenshan area. 
and their positions relative to the earthquake rupture and the Longmenshan fault zone.

After the Wenchuan earthquake, the China Institute for Geo-Environmental Monitoring, Ministry of Land and Resources, divided the disaster-stricken areas into three categories based on geological data obtained from field investigation immediately after the earthquake. The three categories, divided according to the average disaster levels calculated for each administrative unit, are category 1 , category 2 and category 3 , respectively, as shown in Figure 1. We divided the strong motion stations into different groups according to their positions within the three categories. The stations that do not fall into anyone of the three categories were grouped into category 4 , where we think the average disaster level is slight. In this way, we can compare the ground motion intensity with the disaster level on a regional scale.

\section{Newmark displacement evalua- tion model}

\subsection{Relationship between Newmark displace- ment and geological hazard}

From the geological hazard zoning map shown in Figure 1, we can deduce that in the places where the geological hazard is serious, e.g., where the average number of landslides is high, the landslide displacement calculated by the Newmark method [equation (2)] will be large. This is because many of the landslides that took place in this region covered large areas and had longer runout distances. We can also deduce that the ground motion intensity will be strong in these locations, and therefore the corresponding Arias intensity will be high.

Since no critical acceleration data is available and the analysis is not on a concrete slope, we calculate the Newmark displacement for a range of $a_{\mathrm{c}}$ and plot $D_{\mathrm{N}}$ versus $a_{\mathrm{c}}$ for given acceleration time histories. We can then chart these $D_{\mathrm{N}}$ versus $a_{\mathrm{c}}$ curves according to their geological categories, as shown in Figure 2. The figure legends show the corresponding average $I_{\mathrm{a}}$ of the horizontal components.

Comparison of the four charts shown in Figure 2 leads to some observations as below.

In Figure 2, the Newmark displacement is the largest in category 1 , the most serious geological disaster area, followed by category 2 , then category 4 . Category 3 , with relatively fewer observation stations, lacks adequate strong motion data. The general trend in Figure 2 shows that a decrease in geological hazard lev- el (or disaster level) corresponds to a decrease in the Newmark displacement. This indicates that the Newmark displacement is proportional to the seriousness of the geological hazard, including landslides, on a regional scale and can be taken as an indicator of the severity of potential geological disaster. Therefore, based simply on strong motion records, the Newmark displacement can be used to estimate the seriousness of the geological disasters resulting from an earthquake and can provide information for earthquake emergency rescue services and reconstruction works after the earthquake. In this way, earthquake hazard evaluations can be obtained much more quickly than by assessing earthquake intensity, which often takes a long time to be accurately determined after an earthquake.

Strong motion records also relate to the local geological hazard in the same category. Considering locations with the same $a_{\mathrm{c}}$, those locations with larger Newmark displacements are also those with the most serious geological disasters. For example, the Bajiao station (SFBJ in Figure 1) in Shifang city, the Wolong station (WCWL in Figure 1) in Wenchuan county, and the Qingping station (MZQP in Figure 1) in Mianzhu city obtained the top three Newmark displacements during the Wenchuan earthquake; all three are in category 1 , the region of most serious geological disaster according to the average disaster levels. Numerous landslides, many of which were large, were triggered at these three sites. For this reason, we can see that the Newmark displacement can also be a good indicator of the landslide hazard on a local scale. Given a slope and its $a_{\mathrm{c}}$, the larger is the calculated Newmark displacement, the larger the failure probability of the slope is. The Newmark displacement can therefore be used to judge the failure possibility of a slope or disaster seriousness in small region after an earthquake.

From Figure 2, we can see that, at observation points with large Newmark displacement, the corresponding Arias intensity values are large, too. This indicates that the Newmark displacement is proportional to $I_{\mathrm{a}}$, the ground motion parameter that can represent the ground intensity released by the earthquake at a local site. There are some other parameters used more often than $I_{\mathrm{a}}$, but the analysis in our study (Wang et al., $2010 \mathrm{c}$ ) shows that $I_{\mathrm{a}}$ is more related to ground motion intensity and earthquake damage. Therefore, larger $I_{\mathrm{a}}$ implies more energy released. As a result, more serious landslide disaster will be triggered by the earthquake.

The above analyses support the conclusion that the Newmark displacement can well indicate the disaster 

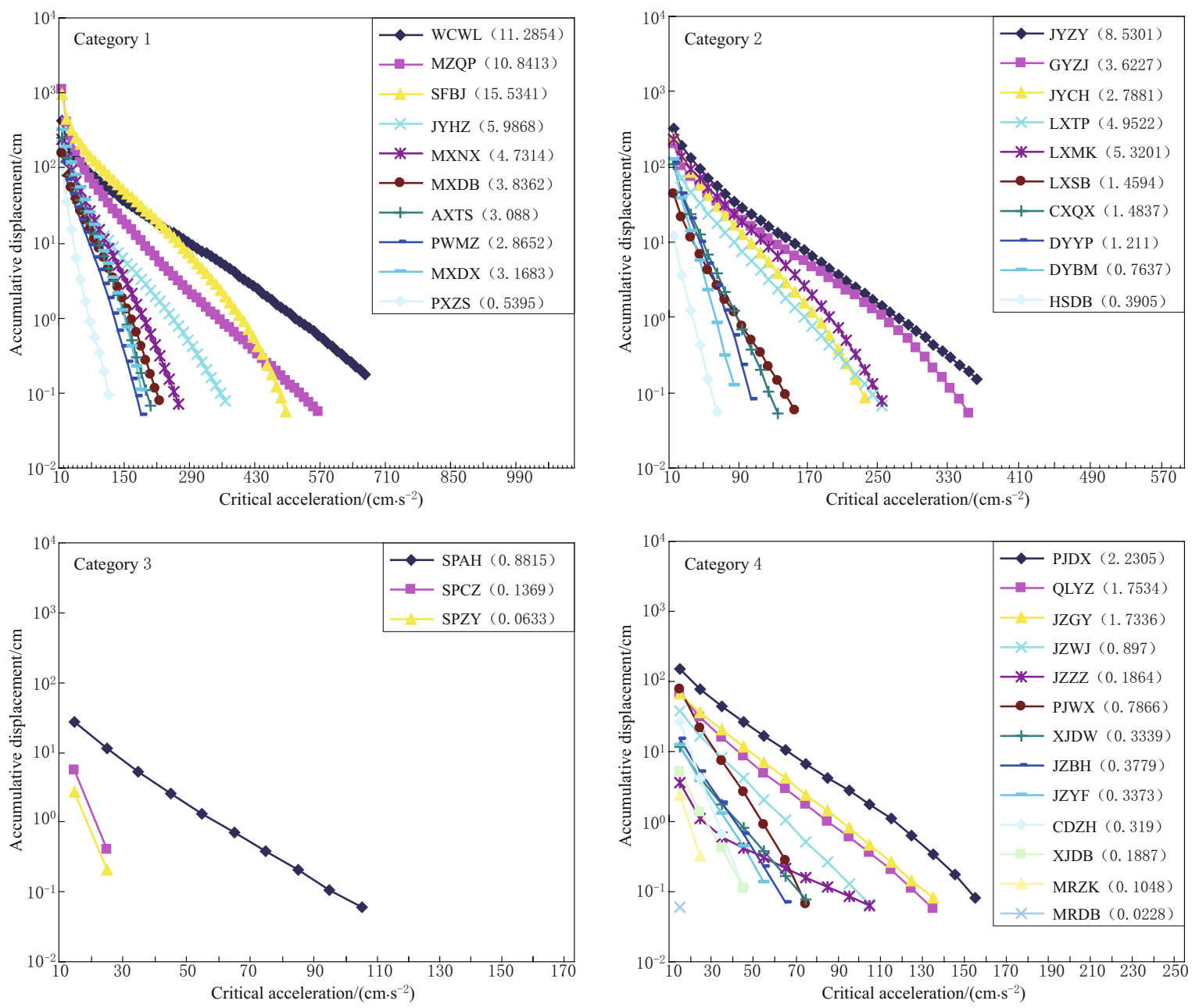

Figure 2 Newmark displacement plotted against critical acceleration for the four geological hazard categories. The legends show the average $I_{\mathrm{a}}$ of the horizontal components from the seismic stations shown in Figure 1.

level, at the same time, it is proportional to the ground intensity. Therefore, the Newmark displacement can be estimated by the ground intensity parameter and be used to evaluate the seriousness of landslide disasters. 3.2 Newmark displacement and Arias intensity

Here, we quantitatively analyze the relationship between the Newmark displacement and Arias intensity. For a given $a_{\mathrm{c}}$ value, we calculate the Newmark displacement for each acceleration time history and get the $D_{\mathrm{N}}$ versus $I_{\mathrm{a}}$ as shown in Figure 3. We calculated four groups of $D_{\mathrm{N}}$ versus $I_{\mathrm{a}}$ values by taking $a_{\mathrm{c}}$ values as $50,100,150$, and $200 \mathrm{~cm} / \mathrm{s}^{2}$, respectively .

As shown in Figure 3, the Newmark displacement is obvious proportional to $I_{\mathrm{a}}$, i.e., it decreases with Arias intensity decreasing. As for the $a_{\mathrm{c}}$, the Newmark displacement is negatively correlated with it, i.e., it decreases with an increase in $a_{\mathrm{c}}$. It is understandable that a larger $a_{\mathrm{c}}$, a parameter reflecting the maximum ground

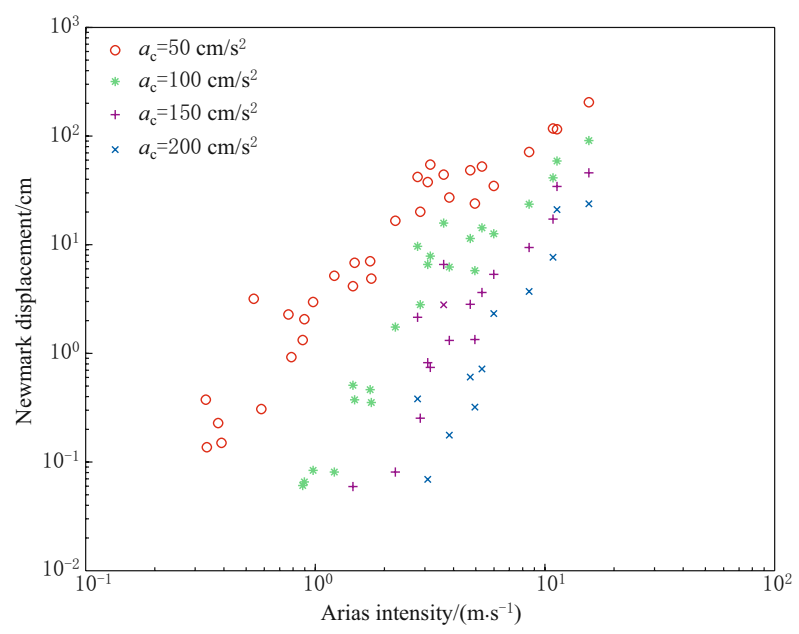

Figure 3 Newmark displacement versus Arias intensity $I_{\mathrm{a}}$ for a range of $a_{\mathrm{c}}$. 
motion intensity a slope can withstand, means that the slope has a higher ability to withstand strong ground motion intensities without failure.

$I_{\mathrm{a}}$ represents the ground motion intensity of an earthquake, while $a_{\mathrm{c}}$ (in the unit of $\mathrm{m} / \mathrm{s}^{2}$ ) represents the ability of a slope to remain stable when the slopes are subjected to an earthquake. Therefore, a higher $a_{\mathrm{c}}$ will result in less Newmark displacement under the same ground motion intensity. On the other hand, the same slope will result in a larger Newmark displacement when subjected to stronger ground motion intensity. Hence, we can construct a model by the following equation:

$$
\lg D_{\mathrm{N}}=a \lg I_{\mathrm{a}}-b \lg a_{\mathrm{c}}+c .
$$

Equation (4) is the improved equation of Jibson et al. (2000). Here, we will prove that this is correct by assessing the regional hazard distribution and quantitatively analyzing the data obtained from the Wenchuan earthquake. The resulting regression equation based on data shown in Figure 3 is

$$
\begin{gathered}
\lg D_{\mathrm{N}}=-4.0687+2.0551 \lg I_{\mathrm{a}}-2.9325 \lg a_{\mathrm{c}}, \\
\sigma=0.11,
\end{gathered}
$$

where $D_{\mathrm{N}}$ is the Newmark displacement in $\mathrm{cm}, I_{\mathrm{a}}$ is the sum of the Arias intensity in the horizontal direction in $\mathrm{m} / \mathrm{s}$, and $a_{\mathrm{c}}$ is the critical acceleration in $\mathrm{g}$.

Equation (5) can be used to estimate the possible Newmark displacement in different parts of the earthquake-affected regions once $a_{\mathrm{c}}$ and $I_{\mathrm{a}}$ are known in advance. Since it is difficult to get the correct $a_{\mathrm{c}}$ value for each slope, the possible $a_{\mathrm{c}}$ values have been evaluated based on the acceleration time history records and landslides triggered by the Wenchuan earthquake, which can be found in another study of our series research (Wang et al., 2009).

Next we will consider the $I_{\mathrm{a}}$. Here, we follow the normal way to get the ground motion parameters, e.g., to establish the attenuation relationship of $I_{\mathrm{a}}$ [equation (6)] based on the same data set mentioned above. The detailed deduction can be found in Wang et al. (2010c).

$$
\begin{aligned}
\lg I_{a} & =-2.96 \lg \left(D_{\mathrm{f}}+42.0\right)+6.39 \\
r & =-0.79, \quad \sigma=0.40
\end{aligned}
$$

where $I_{\mathrm{a}}$ is the sum of the Arias intensity of the horizontal components in $\mathrm{m} / \mathrm{s}$ and $D_{\mathrm{f}}$ is the observation distance to the earthquake rupture in $\mathrm{km}$.

The Newmark displacement estimated in this way is not the actual displacement caused by the earthquake.
Instead, it can be used as an indicator of the failure status (hazard level) of the slopes analyzed above. If a larger $D_{\mathrm{N}}$ is obtained by equation (5), we are sure of a greater possibility of triggered landslides; otherwise, the possibility of landslides will be lower.

\section{Application of the model}

To assess the landslide hazard distribution model, $0.1 \mathrm{~g}$ is taken as a representative critical acceleration value for the Longmenshan area. This $a_{\mathrm{c}}$ value was obtained from previous work (Wang, 2009; Wang et al., 2010a). Combining equations (5) and (6), we calculated the various Newmark displacements as shown in Figure 4. The different critical displacements are selected based on the results usually adopted by many researchers.

In Figure 4, the $29 \mathrm{~km}$ innermost closed curve corresponds to a critical displacement of $10 \mathrm{~cm}$, a value taken by most researchers as the maximum movement that most slopes can undergo when the Newmark displacement model is used (e.g., Wilson and Keefer, 1985; Jibson, 2007). Displacements inside this closed curve are larger than $10 \mathrm{~cm}$, which means that slope failure is almost certain. Huang and Li (2008) reported most landslides and all the large landslides triggered by the Wenchuan earthquake were located within $30 \mathrm{~km}$ of the earthquake rupture. The $29 \mathrm{~km}$ distance contoured in Figure 4 fits well with the actual landslide distributions, although it looks smaller than that for category 1 , the most serious landslide hazard area, which may incorporate some locations with less significant hazard during the averaging process.

The middle closed curve, at a distance of $48 \mathrm{~km}$ from the rupture, corresponds to a critical displacement of $2 \mathrm{~cm}$, a value adopted by Wilson and Keefer (1985) for slopes with brittle material that is common in the Longmenshan area (Huang and Li, 2008; Feng et al., 2007). This curve generally corresponds to category 1 . Within this range, the Newmark displacement is larger than $2 \mathrm{~cm}$, but less than $10 \mathrm{~cm}$, which corresponds to a very high probability of landsliding, especially for those slopes consisting of brittle material.

The outermost closed curve, at a distance of about $100 \mathrm{~km}$ from the earthquake rupture, corresponds to the positions where no accumulated displacement is estimated. Within the $48-100 \mathrm{~km}$ band, the displacement is greater than zero but less than the critical displacement of $2 \mathrm{~cm}$; therefore landslides might still be triggered, but the possibility is decreased. 


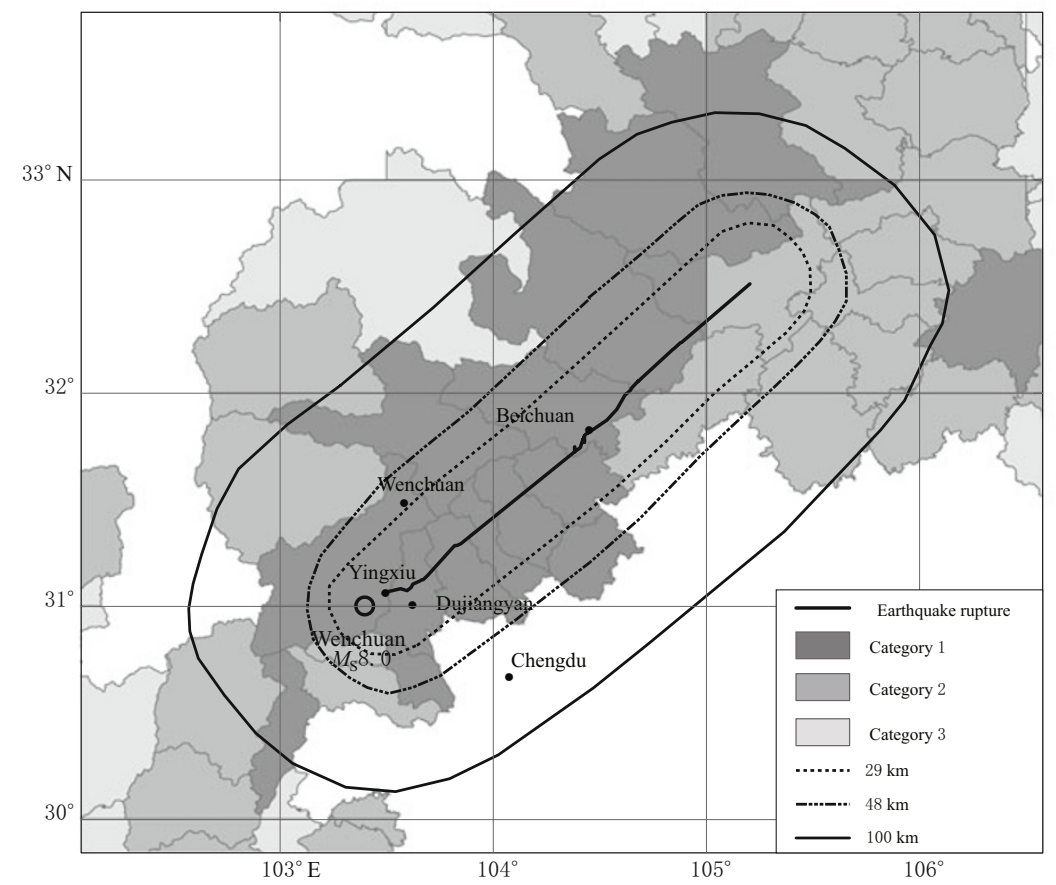

Figure 4 Comparison of the modeled and actual landslide distributions.

This model can provide a general distribution map of regional landslides (Figure 4). However, earthquakeinduced landslides are affected by many factors. Ground motion intensity is not the only important factor; geological and topographical conditions can also exert great influence on landslide occurrences. Therefore, as can be seen from Figure 4, differences may exist between the modeled and actual cases. For example, notice that to the southeast of the earthquake rupture, on the footwall of the fault, landslides hazard is less than modeled, whereas on the northeast side of the rupture, the hazard is more severe. This is due to the thrust faulting mechanism and the propagating effect of the earthquake. Moreover, on the northeast side of the rupture, the geological distribution of loess deposits is quite different from those in the Longmenshan area. Hence, if a more accurate result is needed, many additional factors, including local geology, must be taken into account in the evaluation model.

In spite of the generalized model results, the Newmark displacement method can provide a better result than those obtained by earthquake intensity. The latter produces isoseismal maps with much larger areas where the earthquake intensity is greater than IV (Department of Earthquake Emergency Rescue, China Earthquake Administration, 2008), an earthquake intensity value adopted by many researchers as a threshold for triggering landslides. If this evaluation model could be produced immediately after an earthquake, it would be helpful for decision-making during emergency rescue. For example, it could be used to focus rescue work in regions with greater hazard. If more accurate parameters are provided, the evaluation model can produce better result. This may even be useful for engineering applications during reconstruction work following a large earthquake like Wenchuan.

\section{Conclusions}

Studies of earthquake-induced landslides in China using ground motion parameters have been rare. This paper made an attempt to improve this situation using valuable ground-motion data from the 2008 Wenchuan earthquake. Based on landslide zonation of regional scale and their corresponding Newmark displacements, this paper shows that the Newmark displacement can well describe the spatial distribution of geological disasters. Moreover, the Newmark displacements from different sites in the same category can also reflect the damage situation of the local sites. The calculated result from the selected records demonstrated that the Newmark displacement is proportional to ground motion intensity and is inversely proportional 
to slopes' critical acceleration. Therefore, the Newmark displacement evaluation model was built up for the Wenchuan earthquake in the Longmenshan area. The modeled landslide distribution fits well with the actual case, especially with the most serious geological disaster area.

The study also shows that a model constructed through ground motion parameters can produce better results than the one constructed using earthquake intensity that has been previously used for routine assessments in China. Earthquake intensity measurements have already been replaced by ground motion parameters in earthquake engineering applications ( $\mathrm{Hu}, 2006)$. Therefore, the study on earthquake-induced landslides with ground motion parameters is in agreement with this type of work. By using ground motion parameters, researchers can link the study of landslides with the achievements of the ground motion parameters zoning work developed through earthquake engineering. The research in this paper is only preliminary. Further studies are needed to incorporate more data and design new methods.

Acknowledgements This research is supported by Institute of Crustal Dynamics, China Earthquake Administration (No. ZDJ2010-28) and the National Natural Science Foundation of China (No. 40872209).

\section{References}

Arias A (1970). A measure of earthquake Intensity. In: Hansen R J ed. Seismic Design for Nuclear Power Plants. MIT Press, Massachusetts, Cambridge, 438-483.

Department of Earthquake Emergency Rescue, China Earthquake Administration (2008). Isoseismal map of Wenchuan $M_{\mathrm{S}} 8.0$ earthquake. 2010-09-16. http://www. cea.gov.cn/manage/html/8a8587881632fa5c0116674a018 300cf/_content/08_08/29/1219980517676.html.

Ding Y H, Wang Y Q and Sun J Z (2000). Research on the method for prediction of earthquake-induced landslides and its application to engineering projects. Journal of Engineering Geology 8(4): 475-480 (in Chinese with English abstract).

Feng H F, Zhang Z M and Qian J P (2007). Characteristics of geologic disasters and prevention method in Lixin County, Sichuan Province. The Chinese Journal of Geological Hazard and Control 18(4): 111-114 (in Chinese with English abstract).

Harp E L and Wilson R C (1995). Shaking intensity thresholds for rock falls and slides: evidence from 1987 Whittier Narrows and Superstition Hilss earthquake strongmotion records. Bull Seismol Soc Am 85(6): 1739-1 757.

Hu Y X (2006). Earthquake Engineering. 2nd edition. Seis- mological Press, Beijing, 566pp (in Chinese).

Huang R Q and Li W L (2008). Research on development and distribution rules of geohazards induced by Wenchuan earthquake on 12th. Chinese Journal of Rock Mechanics and Engineering 27(12): 2585-2 592 (in Chinese with English abstract).

Jibson R W (2007). Regression models for estimating coseismic landslide displacement. Engineering Geology 91: 209-218.

Jibson R W, Harp E L and Michael J M (2000). A method for producing digital probabilistic seismic landslide hazard maps. Engineering Geology 58: 271-289.

Keefer D K (2002). Investigating landslide caused by earthquakes - a historical review. Surveys in Geophysics 23: 473-510.

Khazai B and Sitar N (2004). Evaluation of factors controlling earthquake-induced landslides caused by ChiChi earthquake and comparison with the Northridge and Loma Prieta events. Engineering Geology 71(1-2): 7995.

Li X J, Zhou Z H, Yu H Y, Wen R Z, Lu D W, Huang M, Zhou Y N and Cu J W (2008). Strong motion observations and recordings from the great Wenchuan earthquake. Earthquake Engineering and Engineering Vibration 7(3): 235-246.

Liao H (2000). Landslides Triggered by Chi-Chi Earthquake. [M.S. Dissertation]. Taiwan Central University, Zhongli, 99pp (in Chinese with English abstract).

Liu C Z (2008). Disasters induced by the Wenchuan earthquakes, Sichuan, China, and geo-environmental safety. Geological Bulletin of China 27(11): 1907-1 912 (in Chinese with English abstract).

Pradel D, Smith P M, Stewart J P and Raad G (2005). Case history of landslide movement during the Northridge earthquake. J Geotech and Geoenvir Engrg 131(11): 1360-1369.

Saygili G and Rathje E M (2008). Empirical predictive models for earthquake-induced sliding displacements of slopes. J Geotech and Geoenvir Engrg 134(6): 790-803.

Wang L M (2003). Loess Dynamics. Seismological Press, Beijing, 1-430 (in Chinese).

Wang X Y (2009). A Study on Fast Evaluation of Earthquake-Induced Landslides and Their Effects on Earthquake Emergency Rescue. [Ph.D. Dissertation]. Institute of Geology, China Earthquake Administration, Beijing, 170pp (in Chinese with English abstract).

Wang X Y and Nie G Z (2009a). Quick evaluation of distance harmed by earthquake-induced landslides during period of earthquake emergency rescue. Earthquake Research in China 25(3): 333-342 (in Chinese with English abstract).

Wang X Y and Nie G Z (2009b). Characteristics of landslides induced by Wenchuan $M_{\mathrm{S}} 8.0$ earthquake and the preliminary analysis of their relations with ground mo- 
tion parameters. Chinese Journal of Geotechnical Engineering 31(9): 1378-1383 (in Chinese with English abstract).

Wang X Y, Nie G Z and Wang D W (2009). Analysis of landslides induced by Wenchuan earthquake by ground motion records. Chinese Journal of Rock Mechanics and Engineering 28(11): 2369-2376 (in Chinese with English abstract).

Wang X Y, Nie G Z and Wang D W (2010a). Research on relationship between landslides and peak ground accelerations induced by Wenchuan earthquake. Chinese Journal of Rock Mechanics and Engineering 29(1): 83-89 (in Chinese with English abstract).

Wang X Y, Nie G Z and Wang D W (2010b). Relationships between ground motion parameters and landslides induced by Wenchuan earthquake. Earthquake Science 23(3): 233-242.

Wang X Y, Nie G Z and Zhang L (2010c). Relationship between landslides induced by the Wenchuan earthquake and Arias Intensity. Journal of Basic Science and Engineer 18(4): 645-656 (in Chinese with English abstract).

Wilson R C and Keefer D K (1983). Dynamic analysis of a slope failure from the 6 August 1979 Coyote Lake, California, earthquake. Bull Seismol Soc Am 73(3): 863-877.

Wilson R C and Keefer D K (1985). Predicting areal limits of earthquake-induced landsliding. In: Ziony J I ed. Evaluating Earthquakes in the Los Angeles Region-An Earth-Science Perspective. U.S. Geological Survey Professional Paper 1360, 317-345.

Yin Y P (2008). Research on the geo-hazards triggered by Wenchuan earthquake, Sichuan. Journal of Engineering Geology 16(4): 432-444 (in Chinese with English abstract).

Yu H Y, Wang D, Yang Y Q, Lu D W, Xie Q C, Zhang $\mathrm{M}$ Y, Zhou B F, Jiang $\mathrm{W}$ X, Cheng $\mathrm{X}$ and Yang J (2008). The preliminary analysis of strong ground motion characteristics from the $M_{\mathrm{S}} 8.0$ Wenchuan earthquake, China. Technology for Earthquake Disaster Prevention 3(4): 321-336 (in Chinese with English abstract).

Zhou B G and Zhang Y M (1994). Some characteristics of earthquake-induced landslide in Southwestern China. Northwestern Seismological Journal 16(1): 95-103 (in Chinese with English abstract). 